\title{
GCU
}

Glasgow Caledonian

University

University for the Common Good

\section{Musculoskeletal problems and backpack carriage among students in Nigeria}

Abaraogu, U.O.; Duru, D.O.; Imaji, B.; Ezenwankwo, E.F.; Fawole, H.

Published in:

WORK

DOI:

10.3233/WOR-193071

Publication date:

2020

Document Version

Author accepted manuscript

Link to publication in ResearchOnline

Citation for published version (Harvard):

Abaraogu, UO, Duru, DO, Imaji, B, Ezenwankwo, EF \& Fawole, H 2020, 'Musculoskeletal problems and backpack carriage among students in Nigeria', WORK, vol. 65, no. 1, pp. 175-180. https://doi.org/10.3233/WOR193071

\section{General rights}

Copyright and moral rights for the publications made accessible in the public portal are retained by the authors and/or other copyright owners and it is a condition of accessing publications that users recognise and abide by the legal requirements associated with these rights.

Take down policy

If you believe that this document breaches copyright please view our takedown policy at https://edshare.gcu.ac.uk/id/eprint/5179 for details of how to contact us. 
Title: Musculoskeletal problems and backpack carriage among students in Nigeria.

Authors: ${ }^{1}$ Onyinyechukwu Deborah ABARAOGU, ${ }^{1}$ Blessing IMAJI, ${ }^{1}$ Elochukwu Fortune EZENWANKWO, ${ }^{2,3}$ Henrietta Oluwafunmilola FAWOLE, ${ }^{1,3}$ Ukachukwu Okoroafor ABARAOGU,

Affiliations: ${ }^{1}$ Department of Medical Rehabilitation Faculty of Health Science and Technology College Medicine University of Nigeria, Enugu, Nigeria. ${ }^{2}$ Department of Physiotherapy University of Benin, Benin Nigeria. ${ }^{3}$ School of Health and Life Sciences Glasgow Caledonian University, Scotland, United Kingdom.

Correspondence: *Abaraogu Ukachukwu Okoroafor | Department of Medical Rehabilitation Faculty of Health Science and Technology College Medicine University of Nigeria Enugu Campus Enugu 400006 Enugu Nigeria | ukachukwu.abaraogu@unn.edu.ng 


\section{ABSTRACT}

BACKGROUND: The health implication of backpack carriage among school-aged children is a topic of growing research and public health interest. Low weighing backpacks may decrease the risk of musculoskeletal discomforts (MSDs).

OBJECTIVE: To investigate MSDs and their association with backpack carriage practices among secondary school students in eastern Nigeria.

METHOD: Across-sectional study of 404 (243 females and 161 males) secondary school students aged thirteen to seventeen who were residents of Enugu State, Nigeria was conducted. The Modified Standard Nordic Musculoskeletal Questionnaire was adapted and used to collect information onstudents' demographics, musculoskeletal painand backpack carriage. Descriptive statistics (frequencies and percentages) were utilized to summarize results. Chi-square test was used to explore the association between MSD prevalence and backpack carriage practices. Data were analysed using SPSS version 20.0. Alpha level was kept at 0.05 .

RESULTS: The average backpack weight carried by the students in this study was $2.49 \mathrm{~kg}$. Shoulder $(185,45.8 \%)$, neck $(121,30.0 \%)$, upper back $(91,22.6 \%)$ and lower back $(22,5.5 \%)$ in that order were the body regions most affected by MSDs within the last 12 months. More 
females than males reported $\operatorname{MSDs}\left(60.5 \%\right.$ vs $\left.45.2 \% ; x^{2}=8.09, \quad \mathrm{p}=0.04\right)$. Other students'characteristics and backpack carriage related factors were not associated with MSDs.

CONCLUSION: There is a high prevalence of MSDs among secondary school students in this study but it is not related to backpack carriage. Further research is required to identify the factors responsible for the MSDs, as well as suitable interventions to reduce its impact in this population.

Keywords: spinal pain, musculosketal problems, backpack, prevalence.

\subsection{Introduction}

Backpack carriage is a common practice among students[1]. There is evidence that students carry heavy backpacks weighing beyond the recommended safe limits of $10-15 \%$ of their body weight and this has potential consequences such as musculoskeletal discomforts (MSDs) $[2]$.

Increased complaints about MSDs among students have warranted further investigations into MSDs in relation to backpack carriage[3,4]. Evidence suggests that loading the spine with a backpack can lead to exaggerated trunk muscle activity[2,5-8], skeletal system damage, increased fatigue[9], alteration in gait[10], adverse effect on the pulmonary system[11] and possibly lead to spinal deformity[12]. This is particularly worrisome for secondary school students given that their spine is at the critical stage of development[13]. It is therefore intuitive to argue that low weighing backpack may decrease the risk of MSDs in this population.

The health implication of backpack carriage amongschool-aged children is a topic of growing research and public health interest. A study conducted among 140 secondary school students in New Zealand revealed that $77.1 \%$ of these students have experienced MSDs due to 
backpack carriage[14]. A recent study among Indian adolescent school students foundthat $96 \%$ of them carry backpacks weighing above $10 \%$ of their body weight, and this was associated with higher prevalence of musculoskeletal pain[15]. Similarly, in another studyconducted among Ugandan primary school pupils, $35.4 \%$ to $88.2 \%$ of neck, shoulder and upper back pain was due to backpack carriage[4].

Although backpack carriage has been reported to be a common cause of MSDs, and school students habitually use backpacks, no study has been reported on backpack practices of school students in eastern Nigeria. Similarly, the association between backpack use and MSDs in this populationis yet to be documented. Research in this area may promote health programs and policy formulation aimed at reducing the burden of backpack-related MSDs among Nigerian school students. Therefore, this study investigated the prevalence of MSDs and its associations with backpack carriage among secondary school students in Nigeria.

\subsection{Methods}

\subsection{Study design and participants}

This is a cross-sectional study performed amongsecondary school students residing in Enugu State, Nigeria, and is part of an ongoing study (Enugu Safe Backpack Project) that investigates how an array of factors modulate healthy backpack recommendations and musculoskeletal health among school students. This present survey was conducted between March and July 2015 and explored the prevalence of MSDs in relation to backpack carriage among secondary school students aged 13 to 17 years. A total of 404 students were recruited utilizing simple random sampling technique from a larger sample frame drawn from nine secondary schools within Enugu State, Nigeria. The selection ofnine secondary schools within this area was based on a multistage random sampling technique involving all the secondary schools. The sample size of 404 was calculated in order to have $95 \%$ confidence level and a margin error of 5\%[16]. Participants were included in the sample frame only if they were 13 
to 17 years old and had parents or guardians willing to allow them to participate in this study by signing the informed consent form. Participants with any neurological or musculoskeletal deformity or MSDs not related to backpack carriage were excluded from this study.

\subsection{Data collection procedure}

This study was reviewed by the University of Nigeria research ethics committee. Informed consent was obtained prior to the commencement of study from either participant'sparents or guardians after the procedure and the purpose of the research had been clearly explained in writing to participants.

A questionnaire adapted from the modified standard Nordic questionnaire[17,18] was used for the data collection. The questionnaire comprised three parts. The first part assessed participants' demographic characteristics, including the weight of the backpack carried. The second part assessed the duration of backpack carriage, mode of travelling to school, and method of carrying school bag. The third part contained questions from the modified standard Nordic questionnaire which evaluated musculoskeletal pain over the last 12 months, over the last seven days, and any activity limitation due to MSDs.

The students' height (to the nearest $0.1 \mathrm{~cm}$ ) was measured with a meter rule and their weight (to the nearest $0.1 \mathrm{~kg}$ ) was obtained using a scale. The backpack weight (to the nearest $\mathrm{kg}$ ) was measured with a handheld weighing scale. All information was obtained and recorded by the researcher. Subsequently, the students completed the questionnaires. Participants were also allowed to go home with the questionnaire and to submit the completed copy the following day.

\subsection{Data analysis}

Data were analysed using SPSS version 20.0 software. Descriptive statistics (frequency and percentages) were used to summarize participants' demographics, prevalence of MSDs, 
activity limitations and backpack carriage practices among the students. Pearson's Chi-Square test was employed to explore the association between prevalence of MSDs and backpack carriage factors at alpha level 0.05 .

\subsection{Results}

\subsection{Participant demographics and backpack carriage.}

A total of 404 participants (243 females and 161 males) within the age range of 13 to 17 years participated in this study. The mean age of the students was 14.93 years and the average backpack weight was $2.49 \mathrm{~kg}$. The majority of the participants were in year two of senior (67, $36.6 \%)$, or junior $(110,27.2 \%)$ high school. The majority $(83.1 \%)$ of the students reported that they preferred carrying their backpack with the double strap.

\subsection{Prevalence of MSDs}

Shoulder MSDs were the most common for both the 12 month $(185 ; 45.8 \%)$ and the 7 day $(56 ; 14 \%)$ period, whereas the ankle and the knee were the least reported in the last12 months (ankle: 10, 2.5\%; knee:11, 2.7\%) and in the last 7days (ankles: 5, 1.4\%; knee: 8, 2.0\%). The shoulder had the highest level of activity limitation $(56 ; 13.8 \%)$. See details in Table 2.

3.3 Association between factors related to backpack carriage, socio-demographics and prevalence of MSDs

More female (60.5\%) than male (45.2\%) students reported MSDs. Students who carrieda backpack for more than 2 hours a day reported a higher prevalence of MSDs (70.6\%) compared to those who carried it for 30 minutes-1hour $(56.9 \%)$, or $1-2$ hours $(60.2 \%)$. There were increased levels of MSDs among students who preferred carrying their backpack on a single strap $(66,63.5 \%)$ compared with students who preferred double straps $(168,56.5 \%)$. The associations between participants' demographics, backpack carriage characteristics, and prevalence of MSDs are shown in Table3. Except for the association between being female and having an MSD in at least one body region,no other association was found between 
MSDs in any body region and either participants' demographics or backpack carriage characteristics.

\subsection{Discussion}

This survey is a part of an ongoing population-based study aimed at investigating the prevalence of MSDs in relation to backpack carriage among secondary school students and determining the association between the prevalence of MSDs and other factors associated with backpack carriage. The MSDs prevalence was higher among female students compared to male students. This result is similar to those observed in other studies $[19,20]$.

The average backpack weight carried by the students in this survey was $2.49 \mathrm{~kg}$, which was a significantly lower weight than the recommended safe limit for backpack carriage [9][27]. This is the highlight of the findings, and could explain why no association between MSDs and backpack carriage was observed. Most studies have recognized backpack weight as the primary risk factor for MSDs across numerous populations [3][4][9][28]. The reduction of the backpack load carried and the combined effects of healthy backpack carriage, such as wearing a backpack over both shoulders, proper posterior load placement and the use of waist straps can reduce the risk of MSD occurrence among secondary school students. These findings underscore the importance of lighter and well-fitted backpack carriage among secondary school students and its subsequent impact in MSDs injury evasion.

No association was found between the prevalence of MSDs and factors related to backpack carriage. However, although not statistically significant, the longer duration of backpack carriage and the preference to carry backpacks using a single strap was minimally associated with MSDs. The longer a load is carried the more strain and stress the body undergoes and is likely to increase the propensity to MSDs[20,21]. This study revealed a higher prevalence of 
shoulder and neck pain compared to other body regions among the students within the last12months as well as within the last 7 days, and this pattern is similar to what has been reported in previous studies $[21,22]$. The increase inthe anterior positioning of the head when carrying backpacks may in turn exaggerate the saggital shoulder angle[23] and can increase the stress and strain on the neck and shoulder relative to the upper,lower back and other body regions. Further studies assessing biomechanical activities in the regions during static and dynamic motions when backpacks are being carried may confirm this hypothesis.

A number of students reported a limitation of their activities within the last 12 months due to shoulder, neck, upper back, and lower back pain. Potential increase in muscle strain, impingement of the blood vessels and nerves of the shoulder and neck regions, might result in pain and activity limitation[24]. On the other hand, well-padded and adjusted backpack straps could mitigate MSDs due to backpack carriage[2], thus improving activity.

In contrast to a previous finding[4], no significant association was observed in this study between the prevalence of MSDs and factors related to backpack carriages such as backpack weight, duration of carriage and travelling with a backpack, backpack design and carriage patterns. Most of the students who had double strap backpacks and reported symptoms of MSDs may have previously carried their backpacks on one shoulder and this could have led to the occurrence of MSDs in time. In this study data regarding previous backpack practices were not collected; however, carrying school backpack on one shoulder is an inefficient backpack practice that causes uneven distribution of load pressure on the shoulder blade, thus initiating the cascades of events leading to shoulder and spine damages[12,25]. According to a previous study[26], the combined effects of a heavy backpack, duration of a backpack carriage, manipulating and handling of a backpack, the method of carrying, and position of the load on the students'backs are risk factors for musculoskeletal complaints. 


\subsection{Limitations}

The major limitation of this study was its cross-sectional design, which could not permit exploration of causal effects. In addition, the use of a self-report questionnaire in this survey may have led to response bias.

\subsection{Conclusions}

This study found that the average backpack weight carried by the students was within the recommended safe limit for backpack carriage. Although MSD prevalence was generally high, with the shoulder and neck regions and female students more affected, this was not associated with the backpack weight. Studies are needed to understand the factors responsible for the high prevalence of MSDs in this population.

Conflict of interest

The authors have no conflict of interest to report

\section{References}

[1] Ismaila SO. Safe backpack weight limit for secondary school students in Ibadan, Southwestern Nigeria. Alexandria Eng J 2016. 2018; 57(2): 547-554.

[2] Rai A, Agarawal S. Back Problems Due To Heavy Backpacks in School Children. IOSR J Humanit Soc Sci. 2013;10:22-6.

[3] Panicker R, S S. Prevalence of musculoskeletal pain in school going adolescents using school bags - A co-relational research. Int J Ther Rehabil Res. 2014;3:23.

[4] Mwaka ES, Munabi IG, Buwembo W, Kukkiriza J, Ochieng J. Musculoskeletal pain and school bag use: A cross-sectional study among Ugandan pupils. BMC Res Notes. 2014;7(1): 222.

[5] Abaraogu UO, Ezenwankwo EF, Nwadilibe IB, Nwafor GC, Ugwuele BO, Uzoh PC, 
et al. Immediate responses to backpack carriage on postural angles in young adults: A crossover randomized self-controlled study with repeated measures. WORK. 2017;57(1): 87-93.

[6] Hardie R, Haskew R, Harris J, Hughes G. The effects of bag style on muscle activity of the trapezius, erector spinae and latissimus dorsi during walking in female university students. J Hum Kinet. 2015;45:39-47.

[7] Mo SW, Xu DQ, Li JX, Liu M. Effect of backpack load on the head, cervical spine and shoulder postures in children during gait termination. Ergonomics. 2013;56:1908-16.

[8] Motmans RR, Tomlow S, Vissers D. Trunk muscle activity in different modes of carrying schoolbags. Ergonomics. 2006;49:127-38.

[9] Abaraogu UO, Ugwa WO, Onwuka E, Orji E. Effect of single and double backpack strap loading on gait and perceived exertion of young adults. J Back Musculoskelet Rehabil. 2016;29:109-15.

[10] Abaraogu UO, Ugwa WO, Nnodim O, Ezenwankwo EF. Effect of Backpack Strap Patterns on Gait Parameters in Young Adults at Self-Selected Normal and Fast Walking Speeds. PM R. 2017; 9(7): 676-682.

[11] Abaraogu UO, Kizito EB, Okafor UAC, Okoye GC. Effect of variable backpack load and strap option on the pulmonary function of children: A simulation using treadmill walking. WORK 2016;55:525-30.

[12] Kistner F, Fiebert I, Roach K, Moore J. Postural compensations and subjective complaints due to backpack loads and wear time in schoolchildren. Pediatr Phys Ther. $2013 ; 25: 15-24$. 
[13] Dochrell S, Kane C, O'keefe E. Schoolbag weight and the effects of schoolbag carriage on secondary school students. Ergonomics. 2006; 9: 216-222.

[14] Whittfield J, Legg SJ, Hedderley DI. Schoolbag weight and musculoskeletal symptoms in New Zealand secondary schools. Appl. Ergon. 2005; 36: 193-198.

[15] Bryman A. Social research methods Bryman. OXFORD Univ Press 2012:766. doi:10.1017/CBO9781107415324.004.

[16] Bryman A. Social research methods. $4^{\text {th }}$ Ed 2012. Oxford University Press. Oxford UK

[17] Dickinson CE, Campion K, Foster AF, Newman SJ, O’Rourke AMT, Thomas PG. Questionnaire development: an examination of the Nordic Musculoskeletal questionnaire. Appl Ergon. 1992;23:197-201.

[18] Kuorinka I, Jonsson B, Kilbom A, Vinterberg H, Biering-Sørensen F, Andersson G, et al. Standardised Nordic questionnaires for the analysis of musculoskeletal symptoms. Appl Ergon. 1987;18:233-237.

[19] Korovessis P, Repantis T, Baikousis A. Factors Affecting Low Back Pain in Adolescents. J Spinal Disord Tech 2010;23:513-20.

[20] Dianat I, Javadivala Z, Allahverdipour H. School Bag Weight and the Occurrence of Shoulder, Hand/Wrist and Low Back Symptoms among Iranian Elementary Schoolchildren. Heal Promot Perspect. 2011;1:76-85.

[21] Shamsoddini AR, Hollisaz MT, Hafezi R. Backpack weight and musculoskeletal symptoms in secondary school students, Tehran, Iran. Iran J Public Health. 2010;39:120-125. 
[22] Hamzat TK, Abdulkareem TA, Akinyinka OO, Fatoye FA. Backpack-related musculoskeletal symptoms among Nigerian secondary school students. Rheumatol Int 2014;34:1267-1273.

[23] Chansirinukor W, Wilson D, Grimmer K, Dansie B. Effects of backpacks on students: Measurement of cervical and shoulder posture. Aust J Physiother. 2001;47:110-6.

[24] Gold JE, Hallman DM, Hellström F, Björklund M, Crenshaw AG, Mathiassen SE, et al. Systematic review of quantitative imaging biomarkers for neck and shoulder musculoskeletal disorders. BMC Musculoskelet Disord. 2017;18(1): 395.

[25] Geller RJ, Rubin IL, Nodvin JT, Teague WG, Frumkin H. Safe and Healthy School Environments. Pediatr Clin North Am. 2007;54:351-373.

[26] Puckfree T, Silal SP, Lin J. School bag carriage and pain in school children. Disabil Rehabil. 2004; 26:54-59.

[27] Arghavani V, Zamanian Z, Ghanbary A, Hassanzadeh J. Investigation of the relationship between carrying school bags (handbags and backpacks) and the prevalence of musculoskeletal pains among 12-15 year old students in shiraz. Pakistan J Biol Sci. 2014; 17:550-554.

[28] Mohan M, Singh U, Quddus N. Effect of backpack loading on cervical and shoulder posture in Indian School Children. Indian J Physiother Occup Ther. 2007;1:3-12. 
Table 1: Demographics of the participants.

\begin{tabular}{lll}
\hline & $\mathbf{n}$ & $\mathbf{\%}$ \\
\hline Gender & 243 & \\
Female & 161 & 60.1 \\
Male & & 39.9 \\
Class & 41 & \\
JSS 1 & 110 & 10.1 \\
JSS 2 & 31 & 27.2 \\
JSS 3 & 148 & 7.7 \\
SSS 1 & 67 & 36.6 \\
SSS 2 & 7 & 16.6 \\
SSS 3 & & 1.7 \\
Backpack strap & 68 & \\
Single & 335 & 16.9 \\
Double & & 83.1 \\
\hline JSS: Juio seconday sch
\end{tabular}

JSS: Junior secondary school; SSS: Senior secondary school 
Table 2: Prevalence of musculoskeletal disorder and activity limitation among secondary school student at 12 months and 7 days.

\begin{tabular}{|c|c|c|c|c|c|c|c|c|c|c|c|c|}
\hline \multirow[t]{3}{*}{ Variables } & \multicolumn{4}{|c|}{ 12-month } & \multicolumn{4}{|c|}{ 7-day prevalence } & \multicolumn{4}{|c|}{ Activity limitation } \\
\hline & \multicolumn{2}{|l|}{ Yes } & \multicolumn{2}{|l|}{ No } & \multicolumn{2}{|c|}{ Yes } & \multicolumn{2}{|l|}{ No } & \multicolumn{2}{|c|}{ Yes } & \multicolumn{2}{|l|}{ No } \\
\hline & $\mathrm{n}$ & $\%$ & $\mathrm{n}$ & $\%$ & $\mathrm{n}$ & $\%$ & $\mathrm{n}$ & $\%$ & $\mathrm{n}$ & $\%$ & $\mathrm{n}$ & $\%$ \\
\hline Neck & 121 & 30 & 282 & 70 & 40 & 10 & 362 & 90.0 & 46 & 11.4 & 357 & 88.6 \\
\hline Shoulders & 185 & 45.8 & 219 & 54.2 & 56 & 14 & 348 & 86.1 & 56 & 13.8 & 347 & 86.1 \\
\hline Elbow & 75 & 18.7 & 326 & 81.3 & 18 & 4.4 & 384 & 95.5 & 27 & 6.7 & 374 & 93.3 \\
\hline Wrist/hands & 73 & 23.1 & 311 & 77.0 & 25 & 6.2 & 378 & 93.8 & 28 & 6.9 & 375 & 93.1 \\
\hline Upper back & 91 & 22.6 & 311 & 77.4 & 27 & 6.7 & 376 & 93.3 & 32 & 7.9 & 371 & 92.1 \\
\hline Lower back & 22 & 5.4 & 382 & 94.6 & 14 & 3.4 & 389 & 96.5 & 22 & 5.4 & 382 & 94.6 \\
\hline Hip & 22 & 5.4 & 381 & 94.5 & 12 & 3.0 & 392 & 97.0 & 13 & 3.2 & 390 & 96.8 \\
\hline Knee & 11 & 2.7 & 393 & 97.3 & 8 & 2.0 & 398 & 98.0 & 4 & 1.0 & 400 & 99.0 \\
\hline Ankles & 10 & 2.5 & 394 & 97.5 & 5 & 1.4 & 398 & 98.5 & 5 & 1.2 & 399 & 98.8 \\
\hline
\end{tabular}


Table 3: Association between socio-demographic, backpack carriage pattern and 12 months prevalence of musculoskeletal disorder among participants

\begin{tabular}{|c|c|c|c|c|c|c|}
\hline & Yes & & No & & $x^{2}$ & p-value \\
\hline & $\mathrm{n}$ & $\%$ & $\mathrm{n}$ & $\%$ & & \\
\hline \multicolumn{7}{|l|}{ Gender } \\
\hline Male & 66 & 45.2 & 80 & 54.8 & 8.091 & 0.04 \\
\hline Female & 127 & 60.5 & 83 & 39.5 & & \\
\hline \multicolumn{7}{|c|}{ Daily average backpack carriage time } \\
\hline $30-1 \mathrm{hr}$ & 107 & 56.9 & 81 & 43.0 & 1.339 & 0.512 \\
\hline $1-2 \mathrm{hr}$ & 68 & 60.2 & 45 & 33.8 & & \\
\hline$>2 \mathrm{hr}$ & 12 & 70.6 & 5 & 29.4 & & \\
\hline \multicolumn{7}{|c|}{ Walking with backpack to school } \\
\hline Yes & 73 & 62.4 & 44 & 37.6 & 1.129 & 0.507 \\
\hline No & 162 & 56.6 & 124 & 43.4 & & \\
\hline \multicolumn{7}{|c|}{ Preferred carriage pattern } \\
\hline One & 66 & 63.5 & 38 & 36.5 & 3.311 & 0.507 \\
\hline Double & 168 & 56.4 & 130 & 43.6 & & \\
\hline \multicolumn{7}{|c|}{ Position in trunk } \\
\hline Upper hung & 33 & 56.9 & 25 & 43.1 & 0.906 & 0.924 \\
\hline Middle hung & 131 & 58.7 & 92 & 41.3 & & \\
\hline Lower hung & 68 & 57.6 & 50 & 42.4 & & \\
\hline \multicolumn{7}{|l|}{ Strapping } \\
\hline Tightly & 44 & 51.8 & 41 & 48.2 & 0.794 & 0.837 \\
\hline Loosely & 76 & 55.9 & 60 & 44.1 & & \\
\hline Moderately & 113 & 63.1 & 66 & 36.9 & & \\
\hline \multicolumn{7}{|c|}{ Time travelled to school } \\
\hline 5-10mins & 43 & 52.4 & 39 & 47.6 & 2.455 & 0.483 \\
\hline $11-15$ mins & 49 & 58.3 & 35 & 41.7 & & \\
\hline $16-30 \mathrm{mins}$ & 64 & 57.1 & 48 & 42.9 & & \\
\hline$>30 \mathrm{mins}$ & 79 & 61.2 & 50 & 38.8 & & \\
\hline
\end{tabular}

Yes or No indicates responses to presence of MSK disorders; $x^{2}=$ Chi-square 